\title{
Computers or tablets? Choosing devices for educational videogames
}

\author{
Alejandro Romero Hernández ${ }^{1}$, César Díaz-Faes Pérez ${ }^{1}$, Manuel González Riojo ${ }^{1}$, Antonio Calvo Morata ${ }^{1}$, Borja \\ Manero 1 and 2 \\ ${ }^{1}$ Software Engineering and Artificial Intelligence Department (DISIA) \\ University Complutense of Madrid (UCM) \\ Madrid, Spain \\ ${ }^{2}$ Faculty of Arts and Sciences (FAS) \\ Harvard University \\ Cambridge, MA. USA \\ alerom02@ucm.es, cesardiazfaes@ucm.es,manuel.gonzalez@ucm.es, antca101@ucm.es, maneroiglesias@fas.harvard.edu
}

\begin{abstract}
Educational videogames are a very effective tool in the learning process, especially for the current generation, known as the digital natives generation. Many studies have shown their benefits in different fields, using computers and mobile devices, among others. Nevertheless, we have not found in the literature any comparative research between these two platforms. Is one of the platforms more effective than the other to improve the learning process with videogames? In this paper we present the research results by using "The courtesy of Spain", a videogame created to teach its namesake classical theater play's plot by the Spanish playwright Lope de Vega. The videogame was designed to be played in a same way on computers and mobile devices. A quasi-experiment was carried out with control group and experimental group. 141 students between 9 and 11 years old from a school in the Autonomous Community of Madrid (Spain), with no previous knowledge of the play participated in the experiment. The experimental group played on a tablet, while the control group played on a computer. The researchers' first impressions were that the best results would be on tablets due to their ease of use and their great reception among young people. However, the results show statistically significant differences in favor of the computer. They reveal that: 1) the device on which an educational videogame is played is important for its effectiveness and 2) perhaps, in the field of educational videogames, the urgency of replacing the devices that is patent in the industry is not backed up by a greater effectiveness of them.
\end{abstract}

Keywords- Educative games, tecnology, Tablet vs PC, eLearning vs m-Learning, serious games

\section{INTRODUCTION}

There are numerous studies which scientifically shown that videogames are beneficial in many aspects. They can help to improve diverse users' abilities[1]: such as their multitasking abilities [2], helping people with development disorders [3] or elderly age people [3], among many others.

It is clear that videogames are not only related to leisure time, but they are also used as a learning tool. In an educational world in which prevail the use of paper and pen, a videogame well developed and focused on the teaching is an effective learning tool [4], [5]. Many studies have also shown the effectiveness of videogames in a multitude of teaching fields, such as in mathematics [6], [7], in information technology [8], in social sciences [9], in geography [10], in languages [11] or even in literature and classic theater [12]. Moreover, these are not just tools that serve for teaching, different researchers show that educative videogames could be a very effective tool to raise students' interest in the learning process [8], [13] and their motivation to learn [5], [14]-[16].

Little by little, there are progressively more schools that are introducing the use of educational videogames in their classrooms [17]. However, one of the factors to keep in mind is the type of devices to play those educational videogames. Most of the schools have a class with computers, but, there are also some schools, albeit many fewer, that are introducing the tablets in their classrooms.

From the social point of view, it is clear that the use of mobile devices is increasing [18] and it is becoming more common that young people own mobile phones or other similar devices [19]. These young people, who have been adapted to the new technologies since the beginning of their lives, are known as digital natives; are characterized by an innate ability to learn and manipulate new technologies, because they were born in a society in which their usage is spreading, as opposed to the denominated digital immigrants[20].

Mobile devices had got a great welcome and it is common to find houses with several of them [21]. These devices offer a different kind of interaction to the user [22]. Because of this, 
many studies have delved around the effectiveness of these devices as a learning tool in the classroom [17], [23]-[25].

On the other hand, there are computers that have considerably improved over the years and have been used in the majority of recent studies to prove the effectivenes of videogames in education [26]-[28]. But, the way of interacting with these devices has been mantained with no change over the years.

It is important to know, due to the great invasion of mobile devices in society, what platforms are more suitable for learning with videogames. Or whether it has real importance the platform where it is played. In fact, some studies maintain that the devices used could play an important role in the teaching process [29], [30].

Currently, authors do not have evidences of any comparative research in the efficiency of educational videogames among mobile devices and classical computers. This is the main reason for developing this experiment, explained in this paper, aiming to study which device is best adapted for digital natives for a specific videogame.

It is clear the difference among the interaction between a mobile device, with a touch screen, compared to a conventional computer and the classical pointer. For this reason, it was chosen the interaction system Point \& Click for "The courtesy of Spain" videogame, a system that works perfectly on both, computers and mobile devices.

This videogame was designed and developed specifically for our research and it aims to teach its namesake classical theater play's plot by the Spanish playwright Lope de Vega. It is an adventure game created in collaboration of the Spanish Classical Theater National Company (CNTC) and it was based on the staging represented in the Matadero Theater in Madrid during 2014.

The use of educational videogames in the theater field is nothing new. In the research Manero et al. [12], it is proven that games work better among youngsters as motivators for going to the theater than the habitual teacher (traditional teaching).

Our experiment took place in a school in the Madrid Autonomous Community during the month of December in 2015, in which students played the videogame either on computers or on tablets. Furthermore, students answered a pretest and a post-test.

This paper has been structured in the following way. Section II describes about the videogame development process, a tool created to obtain the data needed for the study. Section III describes the corresponding methodology to the experiment carried out. Section IV shows the experiment's results; Section $\mathrm{V}$, the discussion; Section VI identifies the limitations of the study; and, finally the Section VII details the conclusions and future work.

\section{GAME AND RESEARCH QUESTION}

"The Courtesy of Spain" is an adventure videogame based on its namesake theater play by the Spanish playwright Lope de Vega (see Figure 1). Adventure games, since they are story-driven, are the most similar to a theatrical play. Becoming a character in a fictional world can be both pleasurable and a learning experience [31]. Furthermore, the classical dramatic structure fits perfectly within an adventure game. According to Fernandez-Vara [31], these games are designed to "restore behaviors" in a performative sense. The pleasure of restoring specific behaviors in adventure games resides in discovering what the behavior is by finding the solutions to the puzzles. It is like being an actor in a play that one does not have the script for and the script is discovered by trial and error, exploring the world and seeing what works. An adventure game helps the player to restore behavior by giving pointers and information. The design of the space and the player-character are two of the main devices that help the player to figure out what to do [32].

The user's interaction with the game is based on the Point \& Click system, which has already proven itself in educational videogames [32], [33]. Additionally, the player must interact with the environment's characters, who speak and communicate with the player at all times.

The game was based on the theatrical production on the play by Spanish Classical Theater National Company (CNTC) in 2014. The development team's members took part in several of the company's rehearsals, and collaborated with the company's director to move the play's essence into the game. Every set and character in the videogame is based on this production.

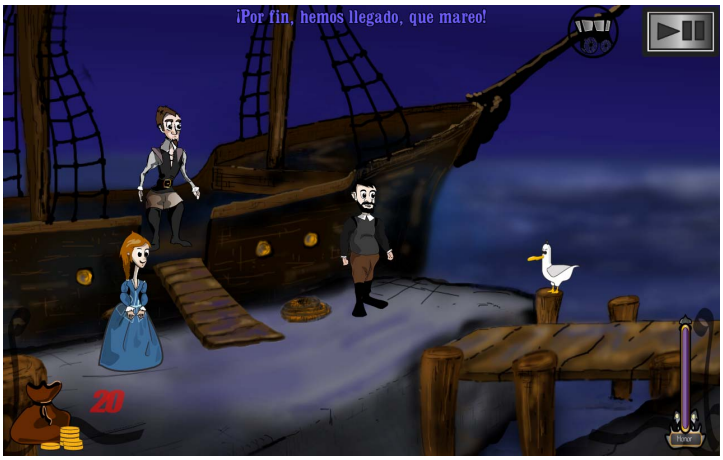

Figure 1 - Screenshot of the game

Furthermore, the characters were given voices that were recorded in a studio and interpreted by several people, including the developers. In addition to giving the characters personality with these voices, the game features music specifically selected for each scene based on the music that appears in the real play. With this, we achieve a more immersive experience for the players.

The game's protagonist is Don Juan de Silva, who, accompanied by his loyal squire, returns to Spain after a failed attempt to find wealth in the Dutch War of Independence, in which Spanish army was defeated. The player must bring Don Juan back home, but must face obstacles and take multiple decisions to do so. 
One of the most difficult challenges of turning a theatrical play into a videogame is the change in narrative. A traditional theatrical play has a linear timeline, while a videogame must have a non-linear timeline in order for the player to make decisions that alter the storyline of the game. This means that we have to find a middle ground between providing the player with more agency with choices that alter the storyline or restrict what the player can do to remain within the original play's storyline.

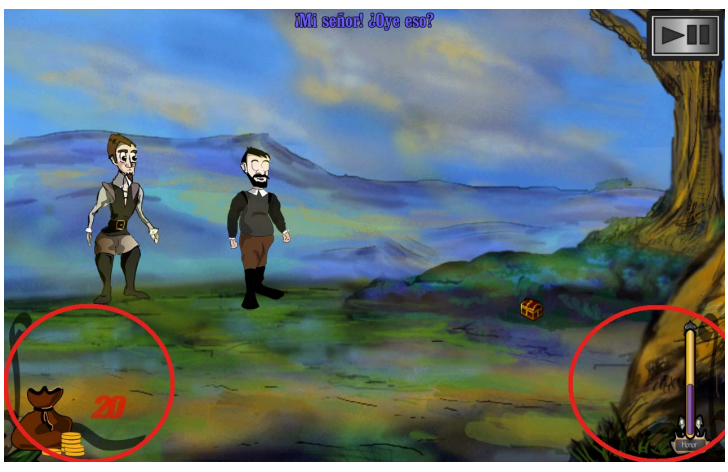

Figure 2 - Courtesy and money in the game

The original play is akin to some American war films, a form of positive propaganda of the American military. In the play, Spanish knights are depicted as courteous individuals capable of facing fear or even death. For this reason, we chose to make courtesy the main theme of the game. This implies a link between the initial plot and a playability element that allows the player to be evaluated based on their actions. In addition to courtesy, another theme was added: money. Requiring the player to value items differently (see Figure 2). Courtesy as well as money directly affect the storyline, opening the possibility of different endings.

Three mini-games were added to the original plot to achieve more engagement from the target audience. In the first one, the player must dodge objects thrown by the villain we are chasing (see Figure 3). In the second, the player must find the origin of some unsettling noises that wake him up in the middle of the night. Finally, the third mini-game is a pistol duel where the player must charge and shoot before the rival shoots him

In a similar fashion, multiple story passages were included that reach different endings to encourage the player to play another round. The plot changes based on the player's choices, which also determine what mini-games the player will play. The aforementioned themes (money and courtesy) are of vital importance to the ending.

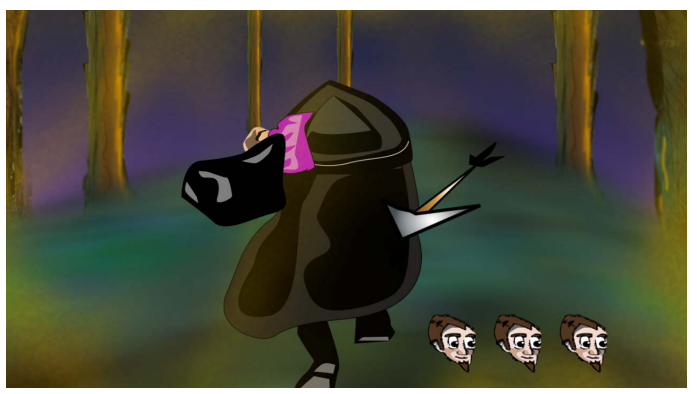

Figure 3 - Mini-game 1: Chasing the villain
The game was developed using Unity's 3D engine, enabling the game to be exported across different platforms. The Dialog Manager, 3rd party software, was also used to manage the characters' dialogs as well as their voices.

The game was designed to be played in the same manner regardless of the device. Testing was carried out in order to ensure this behavior by users and experts. The test involved getting multiple volunteers together to test the videogame on different platforms. At the end of the test, the volunteers were interviewed and a form was distributed to them to maximize the information gathered. Improvements were implemented using the information gathered from the tests and the experts ensured that the game's design is appropriate to be played on both devices.

The main objective of this study was to compare the efficiency of videogames on conventional platforms (computers) and mobile devices (tablets).

Therefore, the main research question is:

RQ1: Are tablets more apt as a learning tool for educational videogames in comparison to computers?

The school where the experiment was carried out, provided us with the students' grades that participated in the experiment. Therefore, in addition to this research question, we also researched whether the students' grades could influence the effectiveness of the game in different devices.

This, however, was not added as a research question owing to the fact that it wasn't one of the starting hypotheses of the experiment.

\section{METHODOLOGY}

Below, the steps followed to carry out the experiment and its features are explained.

\section{A. Participants}

The experiment was carried out with 154 participants, students from the school Benito Pérez Galdós in Madrid. The participants' age range from 9 to 12 years old. $55.2 \%$ of the students were boys, while the remaining $44.8 \%$ were girls. In terms of gender and age, the sample is representative in the student population in the Autonomous Community of Madrid (Spain) [34].

From the total of 154 participants in the experiment, the results obtained from the 12-year-old students were rejected due to they were not part of the target audience for which the videogame was developed. After rejecting these 9 students, the total number of participants was 145 .

One of the first steps, previous to the experiment, was getting in touch with the school in order to know whether the students knew the play's plot, since it was represented in Madrid during 2014, and, because of the scholar excursions, the school might have taken the students there to see the performance. The school management confirmed that their students did not know of the play. Nonetheless, and to avoid bias in the experiment, it was asked, in the initial questionnaire, whether they knew of it. The $97.2 \%$ of participant showed not 
knowing the plot before the experiment. 4 participants of the $145 \mathrm{knew}$ it in advance, so that, the purpose of this experiment is measure how much they (can) learn, the ones who knew it in advance were rejected. For this reason, the final number was 141 useful individuals for the research.

As was mentioned in the introduction of this paper, there are more and more mobile devices at home, and it is typical to find at least one of them in every house. In the case of this experiment, the $99.4 \%$ of participants have any tablet or mobile device at home, so they are used to using them and the experiment did not present any technological challenge to them.

\section{B. Experimental design}

The experiment has a quasi-experimental design (see Figure 4) which consists of three phases:

- Pre-test (5 mins). The participants should fill in a previous questionnaire, before knowing the group in which they were going to be. This helped to avoid the increased effect of motivation for those who have to change the class. In this survey, students filled in the code in order to be anonymous, and to be able to pair up the pre-test, with the videogame, and with the posttest. Furthermore, they completed data like gender and age, and they answered whether they knew in advance "The Courtesy of Spain" play.

- Experience (40 mins). Students were randomly divided into two groups. It was attempted that the distribution was the most homogeneous possible in terms of gender, and the number of participants in the computer room was the same as in the classroom.

Experimental group (Tablet). They stayed in the classroom. Everyone recieved a Tablet with the videogame previously installed. The devices were 10.1 inches Samsung Galaxy Tabs.

Control group (Computer). They went to the computer room where the videogame was installed in every computer. The computers were 15.6 inch Toshiba laptops.

The game is designed to be finished in a class time, it means, over 40 minutes. Besides each student was given some headphones, both tablet and computer, in order to have the most concentration possible getting major immersion in the videogame through the dialogues and the background music.

- Post-test (5 mins). Once the first round finished, participants filled in a second questionnaire that measure what they know about the play's plot. If, for some reason, any participant, ten minutes before finishing the time of the experiment did not have finish the round, this one would be taken as finished and the post-test would be given to fill in. During the experiment it was not necessary to do this in any situation because all of them finished their round with plenty of time to fill in the second questionnaire. The full description of both questionnaires is included in the Instruments section (see section III.C).

The table 1 shows the distribution of participants in their gender and group of intervention.

\begin{tabular}{|c|c|c|c|}
\hline \multirow{2}{*}{ Group } & \multicolumn{2}{|c|}{ Number of participants } & \multirow{2}{*}{ Total } \\
\hline & Male & Female & \\
\hline EG & $40(55.5 \%)$ & $32(44.5 \%)$ & 72 \\
\hline $\mathrm{CG}$ & $34(49.2 \%)$ & $35(50.8 \%)$ & 69 \\
\hline Total & $52.5 \%$ & $47.5 \%$ & 141 \\
\hline
\end{tabular}

Once they completed the questionnaire, participants could play with the videogame again until the assigned time of the experiment finished.

\section{Instruments}

In order to answer the research questions, two questionnaires were developed: a pre-test, in order to answer them before the educational experience, and a post-test, which would be completed at the end.

\begin{tabular}{|l|c|c|}
\hline \multicolumn{1}{|c|}{ Instruments } & $\begin{array}{c}\text { Knowledge about } \\
\text { the plot }\end{array}$ & Grades \\
\hline Type & $\begin{array}{c}\text { Multiple choice } \\
\text { and only one } \\
\text { correct }\end{array}$ & School's grades \\
\hline How is calculated & $\begin{array}{c}1 \text { point each right } \\
\text { question }\end{array}$ & $\begin{array}{c}\text { Grouped by school's } \\
\text { grades }\end{array}$ \\
\hline Number of questions & 8 & 0 \\
\hline Range & $0-8$ & A-F \\
\hline
\end{tabular}

Table 2 - Used instruments

The first part of the pre-test asked for information about age and gender. Furthermore, they were asked to introduce a code, which was handed out previously by the teacher, with a sticker that students had to stick in their chests in order not to lose it, and which served to join the pre and post tests data, and in this way be able to analyze the obtained results respecting the anonymity of each participant. In the second part of the pre-test it is asked, on the one hand, whether they know the theater play's plot, and, on the other hand, what kind of devices they have at home. The reason of this last question is to know the

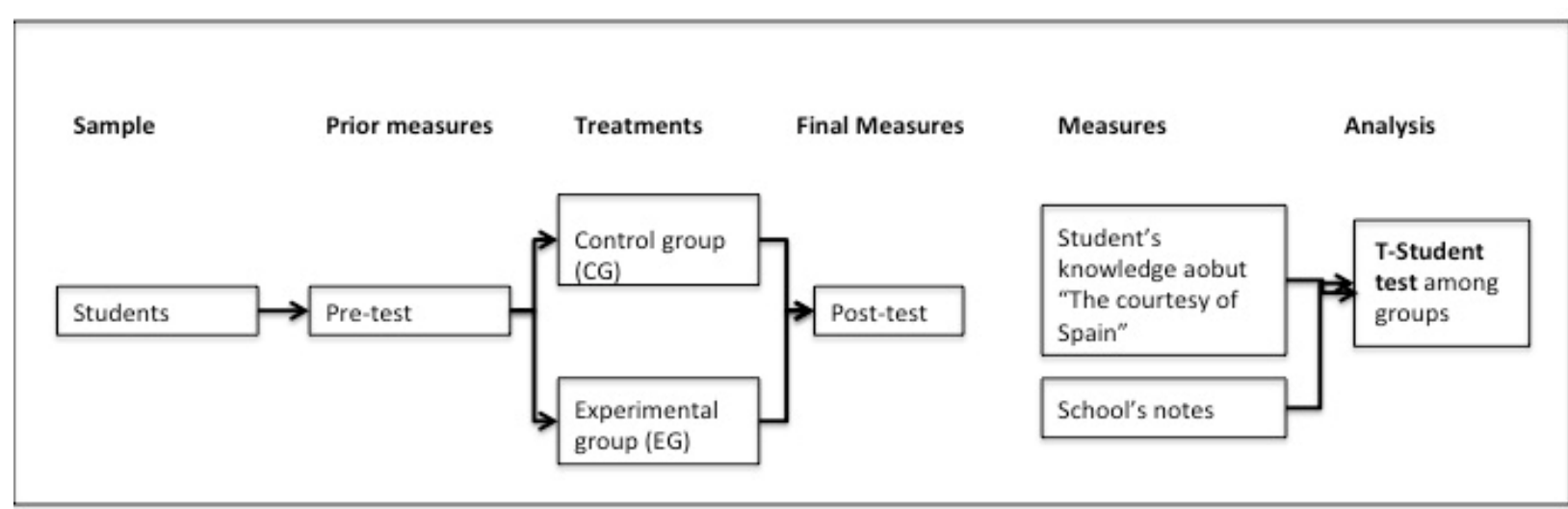


kind of devices they are used to. Also, it asked the approximately number of hours a week they played with each device.

In order to measure how much the students have learned about the play's plot, the post-test contains an 8 questions questionnaire. Questions are multiple-choice with 4 possible answers, of which only one is correct. The questions were designed with different difficulty levels.

IFinally, it was added as a research tool the individual grades, marked on 10 points (usual way to grade in Spain), of each student provided by the school in an anonymous way. They can be seen in a conversion table of marks in [35]. The school provided a list of marks classified using the code given to each student. The marks are joined up from 0 to 4 in the following way (see Table 3):

- F group. It contains the students with a mark exclusively less than 5 (onwards group F). They are the students who are known as Fail in Spain (F).

- D group. It contains the students whose marks were higher or the same as 5 and less than 6 (onwards group D). Sufficient students (D).

- $\quad$ group. It contains the students with higher marks or the same as 6 and less than 7 (onwards group C). Good qualification in Spain (C).

- B group. It contains the students with higher marks or the same as 7 and less than 9 (onwards group B). Very Good students (B).

- A group. The students with higher marks or the same as 9 (onwards group A). Excellent students (A).

\section{RESULTS}

In this section we proceed to analyze data collected during the experiment

\section{A. Comparing effectiveness of games by device}

As initial analysis, and seeking to answer question RQ1, TStudent test is performed for independent samples, since the groups are as well. The study was carried out by using the device used in the experiment (Tablet/Computer) as the independent variable, and the sum of the right answers about the knowledge of the play, performed in the post-test as a dependent variable (Knowledge about the Plot, from now on $\mathrm{KP}$ ). Therefore, the variable KP is measured on a scale of 0 (no right answers) to 8 .

Before performing T-Student, the homogeneity of the variances of the two study groups was tested using Levene's test. In our case, it cannot be assumed that the variance of the groups are homogeneous $(\mathrm{F}=6.194, \mathrm{p}=.014)$.

Taking the above into account to interpret the results, it can be concluded that there is a statistical significance $(T=2.079$, $\mathrm{GL}=132.179, \mathrm{p}=.038)$ regarding the choice of devices to used in classrooms. (See table 4).

\begin{tabular}{|c|c|c|c|}
\hline $\mathbf{T}$ & GL & Sig(Bilateral) & Mean differences \\
\hline 2.091 & 132.179 & $.038^{*}$ & .486 \\
\hline${ }^{*} \mathrm{p}<0.5$ & \multicolumn{2}{|c}{} \\
\hline
\end{tabular}

Table 4 - T-Student on Knowledge about the Plot (KP)

Knowing this significance, we proceed to analyze the statistical descriptions for each group. Firsly, we focus on the respective average in the dependent variable KP and its standard deviation (SD) for each group (see Table 5). These indicate greater effectiveness of computers $(\mathrm{M}=6.32, \mathrm{SD}=$ $1.182)$ over tablets $(\mathrm{M}=5.83, \mathrm{SD}=1.556)$. A clear difference can be observed in the results obtained with an average difference of .486 .

\begin{tabular}{|l|c|c|c|}
\hline \multirow{2}{*}{ DESCRIPTIVES } & \multicolumn{3}{|c|}{ Knowledge about the plot (KP) } \\
\cline { 2 - 4 } & $\boldsymbol{N}$ & Mean & Std deviation \\
\hline EG & 72 & 5.83 & 1.556 \\
\hline CG & 69 & 6.32 & 1.182 \\
\hline \multicolumn{3}{|c|}{ Table 5- Descriptives } \\
\hline
\end{tabular}

Therefore, this analysis has shown statistically significant differences in favor of computers. This proves that the game was more efficient in teaching the play's plot for those students who played it on computers.

\section{B. Effectiveness of videogames depending on students' grades and device used}

With the results obtained in the previous section, and in addition to them, a study on how the device affects the efficiency of our videogame was performed, grouping the students according to their grades (See section III).

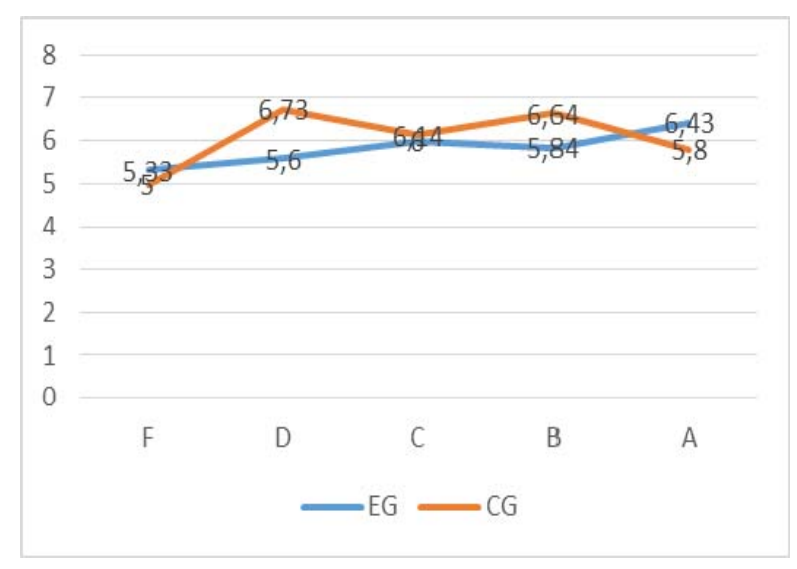

Figure 5 - KP aquired by grades and by device. 
Analyzing data produced by this study (See table 7), groups with opposing tendencies can be observed. As shown in table 1, the group who played with tablets (EG) has a higher average in groups $\mathrm{A}$ and $\mathrm{F}$ (see Figure 5). On the other hand, results in groups $\mathrm{D}, \mathrm{C}$ and $\mathrm{B}$ are consistent with the study performed in the previous section (see Section IV.A), computers higher average than tablets. Table 7 shows averages and standard deviations analyzed by groups and by grades. The uneven distribution of the population (small samples in groups A and F) made impossible to perform a reliable statistical analysis on those data.

\section{Use of devices by students}

The following results (see Table 6) were obtained by analyzing the results from pre-tests asking the participants what kind of devices they have at home and how many hours they spend playing each one of them a week:

\begin{tabular}{|c|c|c|}
\hline Device & Weekly hours played & Standard deviation \\
\hline Mobile device & 6.00 & 6.654 \\
\hline Computer & 1.72 & 2.62 \\
\hline \multicolumn{2}{|c|}{ Table 6 - Weekly hours played per device } \\
\hline
\end{tabular}

In the mobile device section, tablets and mobile phones are taken into account. Table 6 shows the average of playing hours per week of all participants.

\section{Researchers' remarks}

At the end of the experiment, a great deal of the students who played on a Tablet, asked about the possibility of playing another game or some other kind of entertainment, such as YouTube. However, the students who played on a $\mathrm{PC}$ tended to play the game again.

In general, the atmosphere was quiet, although occasionally muttering was caused by the turning points of the game. The atmosphere improved with age, improving the development of the activity.

Although earphones were distributed among the students, some decided to take them off for the sake of comfort. In addition, the researchers noted that, these students were easily distracted, talking to their friends more than the students who opted to use the earphones.

During the experiment, all the students finished their game with plenty of time to finish the second questionnaire. This suggests that the target audience was the adequate for this research.

\section{Discussion}

The research question (RQ1) is answered in this section, and the results obtained for the videogame efficiency depending on the device and the students' grades will be also discussed.

RQ1: Does the tablet work better as a learning tool for educational videogames, improving the knowledge acquired by the players compared to a computer?

No, computers worked better. Results obtained in the results section (IV.A) showed that there are statistical differences $(\mathrm{p}<.05)$ between the control group (computer) and the experimental group (tablet) regarding the results obtained from the survey answers.

Descriptive statistics showed that students in the control group scored .49 higher than students in the experimental group on average (see Table 5) in the post-test this difference being statistically significant. The students from the CG obtained an average score of 6.32, while students from the EG obtained an average score of 5.83 ( 8 being the highest score). The computer, therefore, made our game's efficiency better.

On the analysis of the participants' device usage (see Table 6 ), we can observe that, as average, they devote 3 times more time a week - in spite of the big standard deviations foundplaying on a mobile device than on a computer. Initially, this led us to believe that the game would work out better in students using the Tablet (EG), although the results proved the opposite.

These unexpected results encouraged us to research further in order to establish which group of students obtained better results with which device. To that end, the grades obtained by the students (provided by the school) were also taken in consideration. Therefore, the effect of the grades on the game's efficacy was taken into consideration in both, the control group and the experimental group.

It's vital to mention that the populations division by grade range resulted in unbalanced groups regarding the sample's size (see Table 7). Obtaining groups formed by 5 individuals and others by 22 . This demands caution when analyzing the results of this section, and leads towards a future experiment that further verifies them.

All this being said, we can first state that students belonging to groups $\mathrm{B}, \mathrm{C}$ and $\mathrm{D}$, follow the same pattern, having obtained the best results from the computer group (CG), compared to the ones obtained by the Tablet's (EG)

\begin{tabular}{|c|c|c|c|c|c|c|c|c|c|c|c|c|c|c|c|}
\hline \multirow{3}{*}{ Groups } & \multicolumn{15}{|c|}{ Knowledge about the plot (KP) } \\
\hline & \multicolumn{3}{|c|}{$\mathbf{F}$} & \multicolumn{3}{|c|}{ D } & \multicolumn{3}{|c|}{$\mathbf{C}$} & \multicolumn{3}{|c|}{ B } & \multicolumn{3}{|c|}{$\mathbf{A}$} \\
\hline & $N$ & Mean & $S D$ & $N$ & Mean & $S D$ & $N$ & Mean & $S D$ & $N$ & Mean & $S D$ & & Mean & $S D$ \\
\hline CG & 5 & 5.33 & 1.58 & 15 & 6.73 & 1.28 & 22 & 6.14 & .94 & 22 & 6.64 & 1.09 & 5 & 5.8 & .84 \\
\hline EG & 6 & 5 & 1.86 & 15 & 5.60 & 2.03 & 3 & 6 & 1 & 31 & 5.84 & 1.57 & 7 & 6.43 & .98 \\
\hline
\end{tabular}


group. This would lead us to conclude that for the students that are not placed at the ends, what is the majority of them, the computer obtained far better results than the Tablet. In groups B, the EG (Tablet) score an average of .8 less than the $\mathrm{CG}$ (computer). In $\mathrm{C}$, the EG got .14 less than the CG; and in $\mathrm{D}$, the EG got 1.13 less than the CG.

Nevertheless, the results obtained by students from groups $\mathrm{F}$ and $\mathrm{A}$ are completely the opposite. For these students, the Tablet obtained better results than the computer. In group F, the EG obtained an average of .33 more than the CG, while in A, the EG obtained .63 more points than the CG.

These results may lead to conclude that despite of the fact that the tablet only worked out better for the outstanding students and the failing ones, these students are the minority, and a more detailed study should be done conducted in order to obtain more tangible conclusions. However, this is out of this paper's scope.

It's also interesting to point out that the standard deviations (SD) for all grade groups are always higher in the EG (Tablet) than in the CG (Computer). It means that there's a wider variety in the game's effectiveness on the Tablet than on the Computer meaning that, the game's effectiveness is more diverse on mobile devices, with students that obtain the highest scores mixed with others that get the lowest ones within the same group. Therefore, in the computer (CG) the average scores obtained by the students within the same group are more uniform. For example, for student group D, which is the most uniform regarding the number of students (15 computers, 15 tablets), we observe that (EG) the tablet group's SD is 2.03, while for the computer group (CG) is 1.28. This difference proves that there is a wider diversity of effectiveness for the students that used the Tablet.

\section{LIMITATIONS}

Some limitations were found during the process of this experiment.

Firstly, our study was conducted in a very specific context (i.e., students of age ranging from 9 to 11 years old, a videogame about theatre), making results difficult to generalize. Besides, students were exposed to instruction for a short time (40 mins), which may have prevented certain effects surface to become fully observable. It would be interesting to push this research forward using refined and fully-validated evolutions of the instruments and having longer instruction exposure times, in order to see if other significant differences arise.

The biggest limitation found might be analysis of the experiment's data taking the student's grades into consideration. The unevenness of the group's population makes the results of this part of the study inconclusive.

Finally, we would like to point out that all students were provided with headphones, since the videogame not only has music but also related dialogue; some students found the headphones to be uncomfortable and refused to use them. These students were prompt to copy their classmate's actions instead of finding the best answer by themselves. This fact could also has led to bias.

\section{CONCLUSIONS AND FUTURE WORK}

This experiment proves empirically the importance of the selection of the device as a learning platform within the educational videogames field. The results proved that those students who used a computer to play the game "The Courtesy of Spain" acquired more knowledge about the play's plot than those who played it on a Tablet. Therefore, we argue that the computer was a better learning tool than the mobile device for our videogame.

Even if the tablet seemed like the most effective device at first, since students used it on a daily basis (see Table 6) [32], as mentioned in the above paragraph, the results proved this hypothesis wrong. In this study, our population, in average spend 3 times more time playing with mobile devices than with the computer, despite the fact that they own both devices. Nevertheless, our results could lead us to believe that this generation (digital natives) may consider the Tablet as a leisure oriented device, while the computer is perceived as a work/learning tool.

This study's results recommend, at the very least, being cautious when deciding to change platforms for educational videogames. We are aware of the quickly changing environment in this field, although we wouldn't recommend schools to focus their efforts on purchasing mobile devices as learning tools. We firmly believe in the advantage of the computer, at least at the present moment, as a stronger platform for educational videogames opposed to mobile devices.

For the future, firstly, we plan on creating a new experiment that includes a longer educational intervention so we will assess longer term results in comparison to this study's outcomes. On a second basis, it is essential to recreate this experiment on a wider population in order to research the real effects on the students' grades in the educational videogames.

\section{ACKNOWLEDGMENTS}

The e-UCM research group has been partially funded by Regional Government of Madrid (eMadrid S2013/ICE-2715), by the Complutense University of Madrid (GR3/14-921340), by the Ministry of Education (TIN2013-46149-C2-1-R), by the RIURE Network (CYTED 513RT0471) and by the European Commission (RAGE H2020-ICT-2014-1-644187, BEACONING H2020-ICT-2015-687676).

We acknowledge to Benito Pérez Galdós school, to help us with the experiment. Specially to Marcos González Notario and Ana María Morillo Sánchez. Also, we want to acknowledge to all those who intervened in the game creation, specially to Marcos García-Ergüin, Ángel del Blanco, María Luisa Hondarza, to all who recorded the voices, tested the game and gave us feedback whenever we needed to improve it.

\section{REFERENCES}

[1] A. Sedeno, "Videogames as cultural devices: development of spatial skills and application in learning," Comunicar, vol. 17, no. 34, pp. 183$189,2010$.

[2] D. Chiappe, M. Conger, J. Liao, J. L. Caldwell, and K. P. L. Vu, "Improving multi-tasking ability through action videogames," Appl. 
Ergon., vol. 44, no. 2, pp. 278-284, 2013.

[3] a Torres, "Cognitive effects of videogames on older people," Proc. 7th Intl Conf. Disabil. Virtual Real. Assoc. Technol. with ArtAbilitation, pp. 191-198, 2008.

[4] C. Brom, M. Preuss, and D. Klement, "Are educational computer microgames engaging and effective for knowledge acquisition at highschools? A quasi-experimental study," Comput. Educ., vol. 57, no. 3, pp. 1971-1988, 2011.

[5] G.-J. Hwang, P.-H. Wu, and C.-C. Chen, “An online game approach for improving students' learning performance in web-based problemsolving activities," Comput. Educ., vol. 59, no. 4, pp. 1246-1256, Dec. 2012.

[6] N. Bos and N. S. Shami, "Adapting a face-to-face role-playing simulation for online play," Educ. Technol. Res. Dev., vol. 54, no. 5, pp. 493$521,2006$.

[7] T. Lowrie and R. Jorgensen, "Gender differences in students' mathematics game playing," Comput. Educ., vol. 57, no. 4, pp. 2244-2248, 2011.

[8] M. Papastergiou, "Digital Game-Based Learning in high school Computer Science education: Impact on educational effectiveness and student motivation," Comput. Educ., vol. 52, no. 1, pp. 1-12, Jan. 2009.

[9] J. M. C. López and M. J. M. Cáceres, "Virtual games in social science education,” Comput. Educ., vol. 55, no. 3, pp. 1336-1345, 2010.

[10] H. Tüzün, M. Yılmaz-Soylu, T. Karakuş, Y. İnal, and G. Kızılkaya, “The effects of computer games on primary school students' achievement and motivation in geography learning," Comput. Educ., vol. 52, no. 1, pp. 68-77, 2009.

[11] A. Ravenscroft, "Promoting thinking and conceptual change with digital dialogue games," J. Comput. Assist. Learn., vol. 23, no. 6, pp. 453465, 2007.

[12] B. Manero, J. Torrente, Á. Serrano, I. Martínez-Ortiz, and B. FernándezManjón, "Can educational video games increase high school students' interest in theatre?," Comput. Educ., vol. 87, pp. 182-191, 2015.

[13]H.-Y. Sung and G.-J. Hwang, “A collaborative game-based learning approach to improving students' learning performance in science courses," Comput. Educ., vol. 63, pp. 43-51, Apr. 2013.

[14] M. D. Dickey, "Murder on Grimm Isle: The impact of game narrative design in an educational game-based learning environment," $\mathrm{Br} . J$. Educ. Technol., vol. 42, no. 3, pp. 456-469, May 2011.

[15]C. Cantillo Valero, M. Roura Redondo, and A. Sánchez Palacín, "Tendencias actuales en el uso de dispositivos móviles en educación,” La Educ. Digit., vol. 47, pp. 1-21, 2012.

[16] R. Van Eck, "Building artificially intelligent learning games," in Games and simulations in online learning: Research and development frameworks, D. Gibson, C. Aldrich, and M. Prensky, Eds. Hershey, PA: Information Science, 2007, pp. 271-307.

[17] K. Goodwin, Use of Tablet Technology in the Classroom. NSW Department of Education and Communities 2012.

[18] R. Viriyapong and A. Harfield, "Facing the challenges of the One-TabletPer-Child policy in Thai primary school education," Education, vol.
4, no. 9, 2013.

[19]A. Van Weezel and C. Benavides, "Uso de teléfonos móviles por los jóvenes," Cuad. Inf., no. 25, pp. 5-14, 2009.

[20] P. M. Prensky, "Nativos e Inmigrantes Digitales," Cuadrenos SEK 2.o, no. M-24433-2010, p. 21, 2010.

[21] M. R. V. Cuervo, “Análisis de la difusión de la internet móvil en España," Cuad. económicos ICE, no. 81, pp. 155-174, 2011.

[22]H. Dundar and M. Akcayir, "Tablet vs. paper: The effect on learners' reading performance," Int. Electron. J. Elem. Educ., vol. 4, no. 3, p. 441, 2012.

[23] G. Molnar, "New Learning Spaces ? M-Learning's , in Particular the iPad ' s Potentials in Education," Int. J. Inf. Manage., vol. 7, no. 1, pp. 56$60,2012$.

[24] S. Henderson and J. Yeow, "iPad in Education: A Case Study of iPad Adoption and Use in a Primary School," in 2012 45th Hawaii International Conference on System Sciences, 2012, pp. 78-87.

[25]E. a Walters and M. Baum, "Will the iPad revolutionize education?," Learn. Lead. with Technol., vol. 38, no. 7, pp. 6-7, 2011.

[26] A. Mitchell and C. Savill-Smith, The use of computer and video games for learning: A review of the literature. 2004.

[27] B. Hokanson and S. Hooper, "Computers as cognitive media: Examining the potential of computers in education," Comput. Human Behav., vol. 16, no. 5, pp. 537-552, 2000.

[28] T. M. Connolly, E. a. Boyle, E. MacArthur, T. Hainey, and J. M. Boyle, "A systematic literature review of empirical evidence on computer games and serious games," Comput. Educ., vol. 59, no. 2, pp. 661686, Sep. 2012.

[29] T. Georgiev, E. Georgieva, and A. Smrikarov, "M-learning-a New Stage of E-Learning," in International Conference on Computer Systems and Technologies-CompSysTech, 2004, vol. 4, no. 28, pp. 1-4.

[30]C. Monedero_Morales and J. Monedero_Moya, “Adentrándonos en el laberinto, ¿qué le ocurrirá si juega?,” Rev. Lúdicamente, vol. 4, no. 7, 2015 .

[31] C. Fernandez Vara, "The tribulations of adventure games: integrating story into simulation through performance," Georgia Institute of Technology, 2009.

[32] B. Manero, C. Fernández-Vara, and B. Fernández-Manjón, "E-learning a escena: De La Dama Boba a Juego Serio,” IEEE RITA, 2013.

[33]J. Torrente, Á. Del Blanco, E. J. Marchiori, P. Moreno-Ger, and B. Fernández-Manjón, “<e-Adventure>: Introducing Educational Games in the Learning Process," in IEEE Education Engineering (EDUCON) 2010 Conference, 2010, pp. 1121-1126.

[34]C. de Educación and E. de la C. de Madrid, "Datos y cifras de la Educación 2011-2012,” Estadística la enseñanza en la Comunidad Madrid, 2011.

[35]U. of Granada, "Converting degree chart," 2010. http://internacional.ugr.es/pages/movilidad/tablaconversioncalificacio nes/!. 